5 Germing U, Lauseker M, Hildebrandt B, Symeonidis A, Cermak J, Fenaux P et al. Survival, prognostic factors and rates of leukemic transformation in 381 untreated patients with MDS and del(5q): a multicenter study. Leukemia 2012; 26: 1286-1292.

6 List A, Kurtin S, Roe DJ, Buresh A, Mahadevan D, Fuchs D et al. Efficacy of lenalidomide in myelodysplastic syndromes. N Engl J Med 2005; 352: 549-557.

7 List A, Dewald G, Bennett J, Giagounidis A, Raza A, Feldman E et al. Lenalidomide in the myelodysplastic syndrome with chromosome $5 q$ deletion. $N$ Engl J Med 2006; 355: 1456-1465.

8 Fenaux P, Giagounidis A, Selleslag D, Beyne-Rauzy O, Mufti G, Mittelman M et al. A randomized phase 3 study of lenalidomide versus placebo in RBC transfusion-dependent patients with low-/intermediate-1-risk myelodysplastic syndromes with del5q. Blood 2011; 118: 3765-3776.

9 Kuendgen $A$, Lauseker $M$, List AF, Fenaux $P$, Giagounidis AA, Brandenburg NA et al. Lenalidomide does not increase $A M L$ progression risk in $\mathrm{RBC}$ transfusiondependent patients with Low- or Intermediate-1-risk MDS with del(5q): a comparative analysis. Leukemia 2013; 27: 1072-1079.

10 Schuler E, Giagounidis A, Haase D, Shirneshan K, Büsche G, Platzbecker U et al. Results of a multicenter prospective phase II trial investigating the safety and efficacy of lenalidomide in patients with myelodysplastic syndromes with isolated $\operatorname{del}(5 q)(L E-M O N$ 5). Leukemia 2016; 30: 1580-1582.

11 Padua RA, Guinn BA, Al-Sabah Al, Smith M, Taylor C, Pettersson T et al. RAS, FMS and p53 mutations and poor clinical outcome in myelodysplasias: a 10-year follow-up. Leukemia 1998; 12: 887-892.

12 Fidler C, Watkins F, Bowen DT, Littlewood TJ, Wainscoat JS, Boultwood J. NRAS, FLT3 and TP53 mutations in patients with myelodysplastic syndrome and a del(5q). Haematologica 2004; 89: 865-866.

13 Sallman DA, Komrokji R, Vaupel C, Cluzeau T, Geyer SM, McGraw KL et al. Impact of TP53 mutation variant allele frequency on phenotype and outcomes in myelodysplastic syndromes. Leukemia 2015; 30: 666-673.

14 Jadersten M, Saft L, Pellagatti A, Gohring G, Wainscoat JS, Boultwood J et al. Clonal heterogeneity in the $5 \mathrm{q}$ - syndrome: p53 expressing progenitors prevail during lenalidomide treatment and expand at disease progression. Haematologica 2009; 94: 1762-1766.

15 Tehranchi R, Woll PS, Anderson K, Buza-Vidas N, Mizukami T, Mead AJ et al. Persistent malignant stem cells in del(5q) myelodysplasia in remission. $N$ Engl J Med 2010; 363: 1025-1037.

\title{
LMO2 and IL2RG synergize in thymocytes to mimic the evolution of SCID-X1 gene therapy-associated T-cell leukaemia
}

Leukemia (2016) 30, 1959-1962; doi:10.1038/leu.2016.116

The SCID-X1 disease occurs in males that lack a functional X-linked gene encoding the interleukin 2 receptor subunit gamma (IL2RG) and thus are immuno-deficient (reviewed in Rochman et al. ${ }^{1}$ ). Gene therapy has been a success in curing SCID-X1 in patients receiving autologous $\mathrm{CD}_{3} 4^{+}$-bone marrow cells infected with retroviruses expressing IL2RG. This treatment protocol has, however, produced adverse T-cell effects where clonal T-cell leukaemias arose, and four have insertional mutagenesis of the T-cell oncogene $\mathrm{LMO}^{2} .^{2-5} \mathrm{LMO} 2$ is a T-cell oncogene first discovered via chromosomal translocations in T-cell acute leukaemia (T-ALL) (reviewed in Chambers and Rabbitts ${ }^{6}$ ). It is unclear if the T-cell neoplasias in the SCID-X1 patients are simply due to insertional activation of the $L M O 2$ gene or reflect synergy between LMO2 and IL2RG. ${ }^{7-9}$ Further, the recurrent involvement of $L M O 2$ in SCID-X1 leukaemias is puzzling as other T-cell oncogenes (for example, TAL1/SCL, HOX11 and LYL1) might equally have been targets. This suggests that specific properties of $\mathrm{LMO}_{2}$ per se are required in these adverse events. The oncogenic potential of IL2RG itself also remains controversial. Although it causes T-cell lymphomas in mice transplanted with virally transduced haematopoetic stem cells, ${ }^{10}$ other studies have indicated that IL2RG is not an oncogene. ${ }^{11}$ Here we provide evidence that synergy is required between LMO2 and IL2RG proteins specifically in the T-cell lineage to elicit neoplasias and that additional mutations are required such as Notch 1 mutations like those in human T-ALL. ${ }^{12}$

We made new two transgenic strains where Lmo2 or IL2RG expression uses the Lck-promoter vector (summarised in Figure 1a) to express in thymus $\mathrm{T}$ cells. Lck-Lmo2 transgene expression was confirmed using deep sequencing RNA-seq (Ruggero and Rabbitts, manuscript in preparation), and expression of the IL2RG transgene was confirmed by flow cytometry
(Supplementary Figure 1a). Lck-Lmo2 expression causes a T-cell differentiation blockage at the CD4; CD8 double-negative stage (DN cells) (Supplementary Figure 1d) as first shown with CD2-Lmo2 mice. ${ }^{13,14}$ Expression of the Lck-IL2RG transgene alone did not affect the phenotype of the thymus population (Supplementary Figure 1c).

Double transgenic mice expressing both $L M O 2$ and IL2RG were generated by interbreeding. Both single $L C k-L m o 2$ and double $L c k$-Lmo2; $L c k$-IL2RG transgenic lines develop clonal T-cell neoplasias characterised by thymoma and splenomegaly, after a latency period of several months. Kaplan-Meier survival curves are shown in Figure $1 \mathrm{~b}$. We note a significant difference in the time of appearance of T-cell thymomas in the Lck-Lmo2 mice (mean occurrence of 320 days) compared with the double transgenic Lck-Lmo2; Lck-IL2RG counterparts (mean occurrence of 220 days). The $L c k$-IL2RG single transgenic mice did not show signs of ill health or alteration of thymocyte differentiation. Histological analysis of the single and double transgenic mouse tumours showed similar pathology with homogeneous cellularity in the thymus, loss of distinct red and white pulp in the spleen, and perivascular deposits in pale liver and kidneys (Supplementary Figures S2 and S3). Thus, thymic co-expression of LMO2 and IL2RG proteins synergistically accelerates the rate of T-cell tumour formation compared with $\mathrm{LMO} 2$ alone.

T-cell tumours in Lck-Lmo2 and Lck-Lmo2; Lck-IL2RG mice were clonal as judged by Southern hybridisation analysis of T-cell receptor $\beta$-chain $(\mathrm{Tcr})$ gene rearrangement in thymoma genomic DNA (Supplementary Figures $4 a$ and b). Most of the tumours analysed display rearrangement of one or both Tcrb alleles. The DN surface phenotype of the asymptomatic mice was essentially the same between strains, and the tumours were transplantable. A representative single Lck-Lmo2 mouse (STG21) and two double transgenic mice (DTG21 and DTG22) were compared in more detail by amplification of unique genomic polymerase chain reaction (PCR) products using $V \beta$ and $J \beta P C R$ 
primers (Supplementary Figure 4c) demonstrating bi-allelic Tcrb rearrangements. STG21 has a DN2 phenotype (Figure 1d) similar to the CD2-LMO2 strain. ${ }^{13-15}$ The two double transgenic LCk-Lmo2; Lck-IL2RG mice (DTG21 and DTG22, Figures 1e and f) had either a mixed DN1 and DN2 phenotype or a DN3 phenotype.

The long latency of tumours in the transgenic mice shows that LMO2 is necessary, but not sufficient for T-cell neoplasia and other genetic or epigenetic changes must occur for overt neoplasia. Furthermore, the decrease in the length of this asymptomatic period in Lck-Lmo2; Lck-IL2RG mice indicates the accumulation of these mutations occurs more rapidly and/or different mutations account for the rate increase. A number of mutations have been identified in LMO2-associated human T-ALL, including NOTCH1 mutations that appear in nearly half of cases. ${ }^{12}$ We analysed the Notch 1 gene in the transgenic tumours and found mutation in 65 and $55 \%$ of samples, respectively, of the single and double transgenic tumours. Two types of mutation were observed (Figure 2). A hot spot for mutations was identified in exons 26-27 (Figure 2a) that code for the heterodimerisation domain, responsible for the non-covalent interaction between the trans- activator and the extracellular domains. A second set of common mutations were insertions in exon 34 coding for the proline, glutamic acid, serine, threonine-rich sequence (PEST) domain (Figure $2 \mathrm{~b}$ ). This region of the Notch1 protein regulates degradation and mutations, therein affecting the protein half-life. ${ }^{12}$ The mutations observed in our mouse T-cell neoplasias (both the $L c k$-Lmo2 and $L c k$-Lmo2; $L c k$-IL2RG lines) faithfully recapitulate the mutations observed in human T-ALL. ${ }^{12}$ Thus, transit from asymptomatic and differentiation-blocked thymocytes to clonal neoplasia results from Notch 1 gene mutation in at least half of the cases.

In establishing the dual transgenic model of $L M O 2$ and IL2RG, we sought to elucidate the roles of these two genes in the adverse effects encountered in patients receiving SCID-X1 gene therapy. Our data show that IL2RG is not directly oncogenic in $T$ cells. However, LMO2 and IL2RG functionally co-operate in thymocytes to accelerate tumourigenesis as IL2RG shortens the period in which cells acquire mutations required to drive leukaemia. Most likely, because LMO2 invokes thymocytes differentiation block at DN2/DN3 stages where IL2RA (CD25) is expressed, linking its effect a

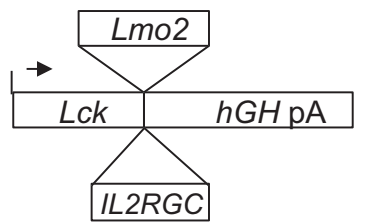

b

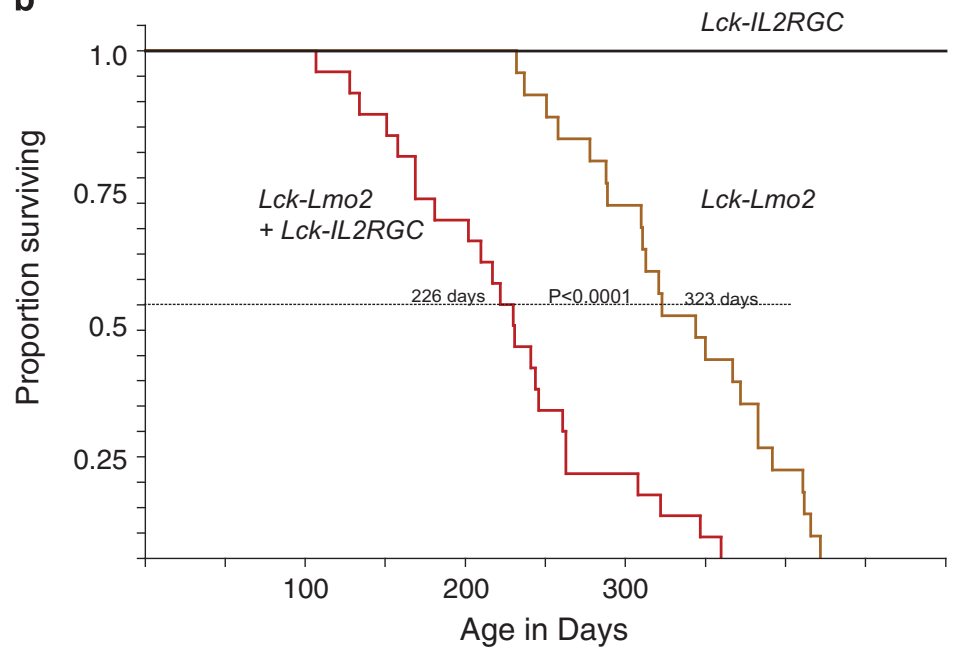

C

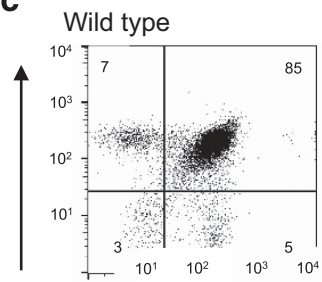

d

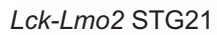

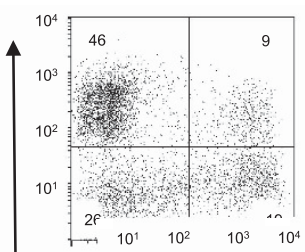

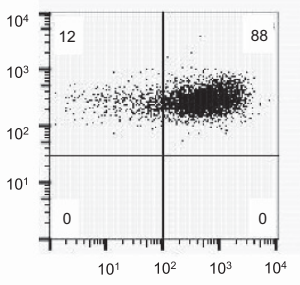

e Lck-IL2RgC x Lck-Lmo2 DTG21

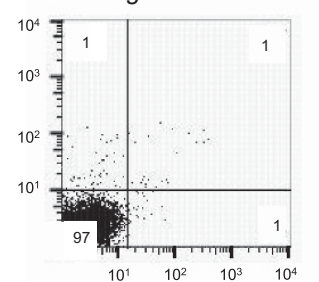

f

Lck-IL2RgC x Lck-Lmo2 DTG22

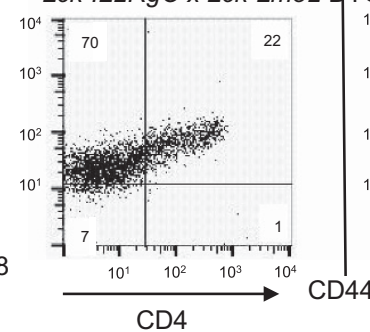

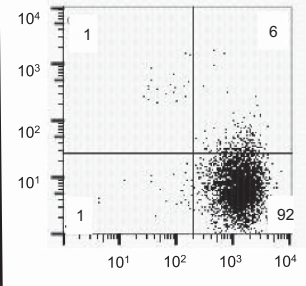

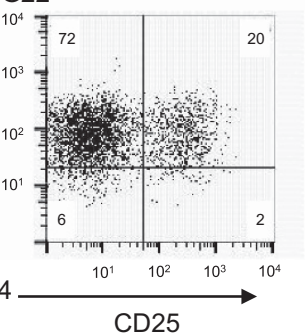

Figure 1. T-cell tumours in $L c k-L m o 2$ and $L c k-L m o 2 ; L c k-I L 2 R G$ transgenic mice. (a) Transgenic mice were made expressing $L m o 2$ and/or IL2RG in thymocytes. Cohorts of mice expressing either LMO2 or IL2RG or both transgenes were monitored over an 18-month period, and disease assessed by macroscopic changes to habit and subsequent post-mortem. (b) Kaplan-Meier comparison of disease incidence. The Lmo2 and IL2RG double transgenic $(n=21)$ group developed T-cell neoplasia at an accelerated rate compared with single $L m o 2$ transgenic mice $(P$-value $<0.0001)(n=22)$. Single IL2RG mice did not develop tumours $(n=22)$. (c-f) Flow cytometry of CD4, CD8, CD25 and CD44 of a wildtype C57BI6 mouse (male; 21 weeks) (c) secondary tumours derived from the spleen of Rag1 null recipient mice transplanted with Lck-Lmo2 STG1 (d) Lck-Lmo2; Lck-IL2RG DTG21 (e) or Lck-Lmo2; Lck-IL2RG DTG22 (f) primary tumours. Cells were gated on CD90.2-positive population. 
a

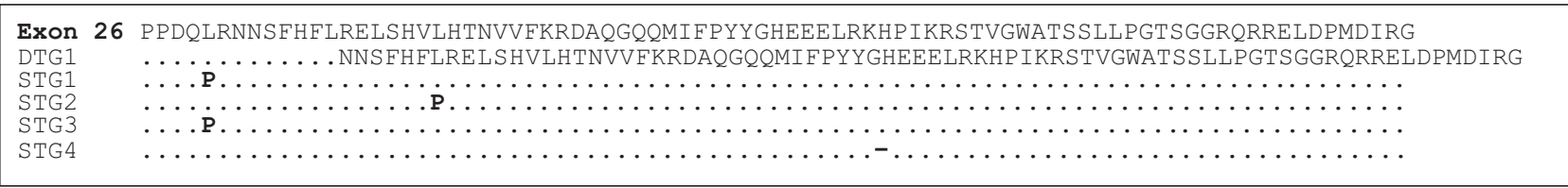

\begin{tabular}{|l} 
ExOn \\
27
\end{tabular}

b

\begin{tabular}{|c|c|}
\hline $\begin{array}{l}\text { Exon } 34 \\
\text { DTG5 } \\
\text { DTG6 } \\
\text { DTG7 } \\
\text { DTG8 } \\
\text { STG6 } \\
\text { STG4 } \\
\text { STG7 } \\
\text { STG10 }\end{array}$ & 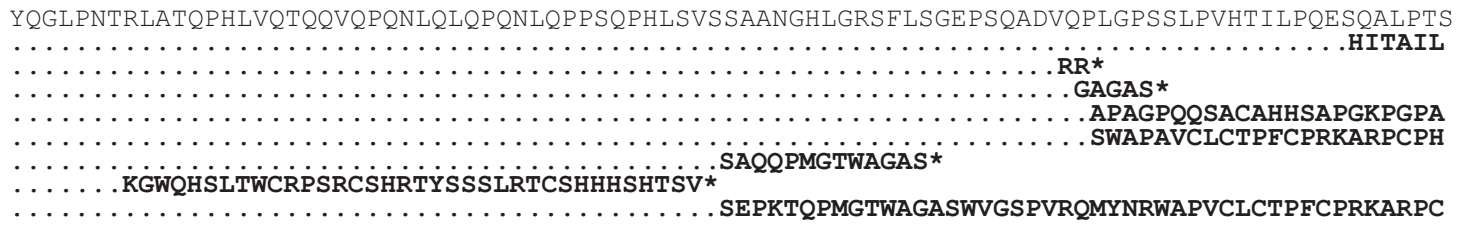 \\
\hline
\end{tabular}

Figure 2. Notch1 mutations in transgenic tumours. Genomic DNA from thymoma samples were analysed by MCA for potential Notch1 mutations at exon 26, 27 and 34 regions. Positive samples were sequenced across the appropriate exon regions. Mutated amino acids are shown in bold. Point mutations occur in exons 26 and 27 (a), except one Lck-Lmo2; Lck-IL2RG tumour that has a frame shift in exon 26 . Exon 34 (b) changes result in frame shifts.

to the other IL2R chain, IL2RG. It is intriguing as IL2RG is required to form a higher affinity IL2 receptor with IL2RA, whose downstream signalling affects T-cell proliferation and differentiation. ${ }^{1}$ The LMO2 and IL2RG co-operation that causes the faster tumour aetiology may be a consequence of LMO2-induced blockade at DN2/3 and expression of transgenic IL2RG resulting in IL2 receptor precluding these cells entering a prolonged resting state. Finally, it is noteworthy that not all SCID-X1 gene therapy patients developed leukaemia, although some had clones with detectable retroviral insertion at $\mathrm{LMO} 2 .^{16}$ This is presumably because LMO2 is not sufficient for T-cell oncogenesis ${ }^{14}$ and secondary mutations are needed for overt disease, such as Notch1. In our transgenic model, the high penetrance of T-cell neoplasia reflects the high number of T cells available for random secondary mutations to occur.

In our model, ectopic expression of $L M O 2$ and IL2RG is restricted to the T-cell lineage, establishing that co-expression of these genes in SCID-X1 therapy patients is sufficient to drive development of leukaemia. Although SCID-X1 patients with the requisite retroviral insertion may co-express $L M O 2$ and IL2RG in bone marrow pluripotent cells, it seems likely that leukaemogenesis is only initiated once those cells arrive in the thymus to be subjected to the LMO2-mediated differentiation block. Thus, LMO2 gene expression in bone marrow progenitors is not relevant per se, but rather the probability of inserting into any open chromatin gene is related to the dose of transducing retrovirus and the number of $\mathrm{CD}_{3} 4^{+}$HSC transduced for the gene therapy. ${ }^{7}$ In Wiskott-Aldrich gene therapy, patients also developed leukaemias showing $L M O 2$ activation through retroviral insertion. ${ }^{17}$ Interestingly, several of these leukaemias had secondary insertions at the TAL1 gene, known to enhance tumourigenesis in mice, ${ }^{14}$ or the $L Y L 1$ gene encoding another LMO2 interaction partner. ${ }^{18}$
Correction of the IL2RG deficiency in SCID-X1 is a significant success that was tempered when patients developed therapyrelated T-cell leukaemia. It is now clear that the adverse T-cell effects in the patients resulted from an unpredicted consequence of insertional mutagenesis into a gene (LMO2) that has the power, when aberrantly activated, to affect the differentiation of the very cells that are defective in SCID-X1.

\section{CONFLICT OF INTEREST}

The authors declare no conflict of interest.

\section{ACKNOWLEDGEMENTS}

The work was supported by the Medical Research Council, UK (grant MR/J000612/1), Bloodwise (grant 12051) and the Wellcome Trust (099246/Z/12/Z). We are indebted to Alan Forster and Lesley Drynan for work with the Lck-transgenic mice. The WIMM flow facility is supported by the MRC HIU; MRC MHU (MC_UU_12009); NIHR Oxford BRC and John Fell Fund (131/030 and 101/517), the EPA fund (CF182 and CF170), and the WIMM Strategic Alliance awards G0902418 and MC_UU_12025.

\footnotetext{
K Ruggero $^{1}$, O Al-Assar ${ }^{1}$, JS Chambers ${ }^{1}$, R Codrington ${ }^{1,2}$, T Brend ${ }^{1,3}$ and TH Rabbitts ${ }^{1}$

${ }^{1}$ Weatherall Institute of Molecular Medicine, MRC Molecular Haematology Unit, University of Oxford, John Radcliffe Hospital, Oxford, UK and

${ }^{2}$ ABeterno Technologies Ltd, Cambridge, UK E-mail: terence.rabbitts@imm.ox.ac.uk ${ }^{3}$ Current address: Leeds Institute of Cancer \& Pathology, St James's University Hospital, Leeds, UK.
} 
1962

\section{REFERENCES}

1 Rochman Y, Spolski R, Leonard WJ. New insights into the regulation of T cells by gamma(c) family cytokines. Nat Rev Immunol 2009; 9: 480-490.

2 Hacein-Bey-Abina S, von Kalle C, Schmidt M, Le Deist F, Wulffraat N, Mclntyre E et al. A serious adverse event after successful gene therapy for X-linked severe combined immunodeficiency. N Engl J Med 2003; 348: 255-256.

3 Hacein-Bey-Abina S, Von Kalle C, Schmidt M, McCormack MP, Wulffraat N, Leboulch $\mathrm{P}$ et al. LMO2-associated clonal T cell proliferation in two patients after gene therapy for SCID-X1. Science 2003; 302: 415-419.

4 Hacein-Bey-Abina S, Garrigue A, Wang GP, Soulier J, Lim A, Morillon E et al. Insertional oncogenesis in 4 patients after retrovirus-mediated gene therapy of SCID-X1. J Clin Invest 2008; 118: 3132-3142.

5 Howe SJ, Mansour MR, Schwarzwaelder K, Bartholomae C, Hubank M, Kempski H. Insertional mutagenesis combined with acquired somatic mutations causes leukemogenesis following gene therapy of SCID-X1 patients. J Clin Invest 2008; 118: 3143-3150.

6 Chambers J, Rabbitts TH. LMO2 at 25 years: a paradigm of chromosomal translocation proteins. Open Biol 2015; 5: 150062.

7 McCormack MP, Rabbitts TH. Activation of the T-cell oncogene LMO2 after gene therapy for X-linked severe combined immunodeficiency. N Engl J Med 2004; 350: 913-922.

8 Dave UP, Jenkins NA, Copeland NG. Gene therapy insertional mutagenesis insights. Science 2004; 303: 333.

9 Dave UP, Akagi K, Tripathi R, Cleveland SM, Thompson MA, Yi M et al. Murine leukemias with retroviral insertions at $\mathrm{Lmo} 2$ are predictive of the leukemias induced in SCID-X1 patients following retroviral gene therapy. PLoS Genet 2009; 5: e1000491.

10 Woods NB, Bottero V, Schmidt M, von Kalle C, Verma IM. Gene therapy: therapeutic gene causing lymphoma. Nature 2006; 440: 1123.

11 Pike-Overzet K, de Ridder D, Weerkamp F, Baert MR, Verstegen MM, Brugman MH et al. Ectopic retroviral expression of LMO2, but not IL2Rgamma, blocks human T-cell development from CD34+ cells: implications for leukemogenesis in gene therapy. Leukemia 2007; 21: 754-763.
12 Weng AP, Ferrando AA, Lee W, Morris JPt, Silverman LB, Sanchez-lrizarry C et al. Activating mutations of NOTCH1 in human T cell acute lymphoblastic leukemia. Science 2004; 306: 269-271.

13 Larson RC, Osada H, Larson TA, Lavenir I, Rabbitts TH. The oncogenic LIM protein Rbtn2 causes thymic developmental aberrations that precede malignancy in transgenic mice. Oncogene 1995; 11: 853-862.

14 Larson RC, Lavenir I, Larson TA, Baer R, Warren AJ, Wadman I et al. Protein dimerization between Lmo2 (Rbtn2) and Tal1 alters thymocyte development and potentiates T cell tumorigenesis in transgenic mice. EMBO J 1996; 15: 1021-1027.

15 McCormack MP, Young LF, Vasudevan S, de Graaf CA, Codrington R, Rabbitts TH et al. The Lmo2 oncogene initiates leukemia in mice by inducing thymocyte self-renewal. Science 2010; 327: 879-883.

16 Deichmann A, Hacein-Bey-Abina S, Schmidt M, Garrigue A, Brugman MH, Hu $J$. Vector integration is nonrandom and clustered and influences the fate of lymphopoiesis in SCID-X1 gene therapy. J Clin Invest 2007; 117: 2225-2232.

17 Braun CJ, Boztug K, Paruzynski A, Witzel M, Schwarzer A, Rothe $M$ et al. Gene therapy for Wiskott-Aldrich syndrome--long-term efficacy and genotoxicity. Sci Transl Med 2014; 6: 227ra33.

18 Wadman I, Li J, Bash RO, Forster A, Osada H, Rabbitts TH et al. Specific in vivo association between the bHLH and LIM proteins implicated in human $\mathrm{T}$ cell leukemia. EMBO J 1994; 13: 4831-4839.

(i) This work is licensed under a Creative Commons Attribution 4.0 International License. The images or other third party material in this article are included in the article's Creative Commons license, unless indicated otherwise in the credit line; if the material is not included under the Creative Commons license, users will need to obtain permission from the license holder to reproduce the material. To view a copy of this license, visit http://creativecommons.org/licenses/ by/4.0/

Supplementary Information accompanies this paper on the Leukemia website (http://www.nature.com/leu) 